\title{
Arteriovenous haemangioma of the vas deferens: a case report and literature review
}

\author{
Facai Zhang ${ }^{1,2 \#}$, Yunjin Bai ${ }^{1 \#}$, Xiaoming Wang ${ }^{1 \#}$, Yin Tang', Yubo Yang ${ }^{1}$, Huan $\mathrm{Hu}^{3}$, Zeyu Chen ${ }^{1}$, Ao $\mathrm{Li}^{1}$, \\ Dengxiong Li ${ }^{1}$, Dechao Feng ${ }^{1}$, Zhiqiang Yang ${ }^{1}$, Ping Han ${ }^{1,4}$ \\ ${ }^{1}$ Department of Urology/Institute of Urology, West China Hospital, Sichuan University, Chengdu, China; ${ }^{2}$ Department of Urology, the Affiliated \\ Hospital of Guizhou Medical University, Guiyang, China; ${ }^{3}$ School of Clinical Medicine, Guizhou Medical University, Guiyang, China; ${ }^{4}$ Department \\ of Urology, The Second People's Hospital of Yibin, Yibin, China \\ \#These authors contributed equally to this work. \\ Correspondence to: Ping Han. Department of Urology/Institute of Urology, West China Hospital, Sichuan University, Sichuan Province, China, No.37 \\ Guoxue Alley, Wuhou District, Chengdu 610041, China. Email: hanpingwch@163.com.
}

\begin{abstract}
Arteriovenous haemangioma of the vas deferens is an extremely rare entity in clinical practice. To date, there have been no clinical or pathological cases reported in Medline, Embase or other published English literature. Herein, a 50-year-old male who presented with right scrotal pain for 4 years after vasectomy was admitted to our hospital. One painful nodule was palpable in the right scrotum on physical examination. Color Doppler ultrasound merely showed dilation of the epididymis and no additional information concerning the painful nodule in the right scrotum. Moreover, the laboratory test results were all within normal limits. Ibuprofen was administered to the patient for 2 months with a poor effect, and then spermatic cord block significantly relieved his symptoms. This patient underwent resection of the right painful nodule of the vas deferens under medical advice. Postoperative pathological examinations showed arteriovenous haemangioma of the vas deferens. There were no obvious complications after arteriovenous haemangioma excision, and the right scrotal pain was significantly relieved 1 month later. This article reminds urologists and oncologists that haemangioma can involve the vas deferens and, in addition to spermatic granuloma, might be a cause of post-vasectomy pain syndrome. Cauterization of the vas deferens might have a potential relationship with haemangioma.
\end{abstract}

Keywords: Haemangioma; vas deferens; vasectomy; post-vasectomy pain syndrome

Submitted Aug 09, 2020. Accepted for publication Oct 28, 2020.

doi: $10.21037 /$ tau-20-1156

View this article at: http://dx.doi.org/10.21037/tau-20-1156

\section{Introduction}

Haemangioma is a benign tumor characterized by the proliferation of vascular endotheliocytes, and it often involves the head, neck, trunk and limbs $(1,2)$. According to its pathological features, haemangioma can be classified as capillary haemangioma, cavernous haemangioma or arteriovenous haemangioma (1-3). Haemangioma of the vas deferens is an extremely rare entity in clinical practice. To date, there have been no cases reported in Medline, Embase or other published English literature. Herein, we present a case of haemangioma of the vas deferens, in accordance with the CARE and SCARE reporting checklists (available at http://dx.doi.org/10.21037/tau-20-1156).

\section{Case presentation}

A 50-year-old male was referred to our hospital with a chief complaint of intermittent right scrotal pain for 4 years after vasectomy. The pain was induced by heavy physical labor or sexual intercourse and could radiate to the right inner thigh, seriously affected his labor ability and quality of life. We reviewed the patient's previous surgery records and found that two $1 \mathrm{~cm}$ incisions were made in the scrotum, 

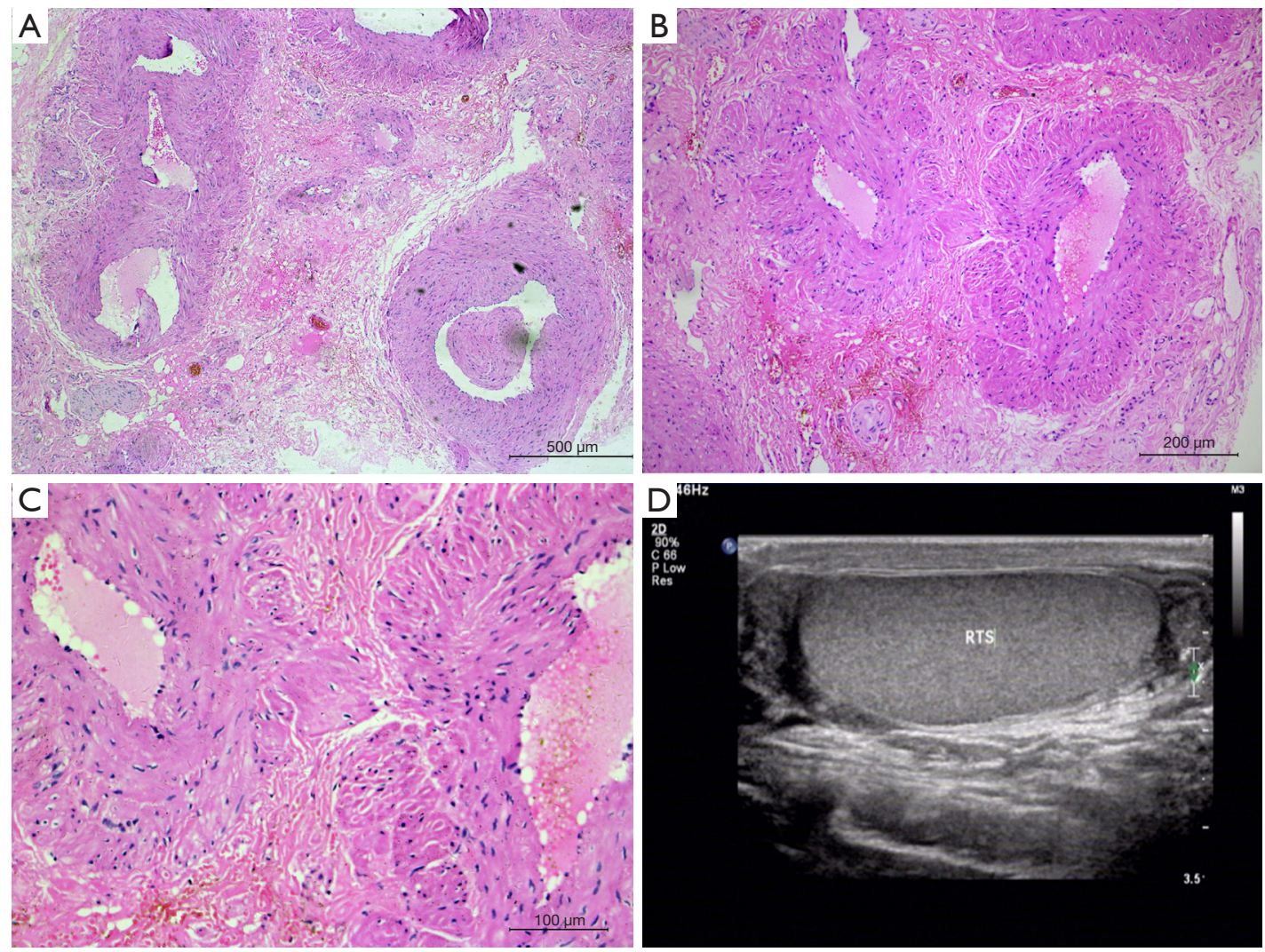

Figure 1 Pathological and imaging examinations of arteriovenous haemangioma of the vas deferens. (A,B,C) The pathological sections of the arteriovenous haemangioma stained by haematoxylin and eosin (HE), magnified 50, 200, and 400 times respectively. (D) The ultrasound revealed no additional information about the painful nodule in the right scrotum.

and the bilateral vas deferens were isolated and excised with a size of approximately $0.6 \mathrm{~cm}$ with tissue scissors. The two ends were ligated with silk sutures and cauterized with an electrotome, a procedure that was performed under local infiltration anesthesia in March 2015. Three months ago, a magnetic resonance imaging (MRI) examination in the local hospital showed that the lesion located in the right vas deferens demonstrated inhomogeneous hypointense signals on T1WI, and inhomogeneous iso- and hyperintense signals on T2WI, which was in accordance with inflammatory disease (only the MRI examination report was available). Physical examination revealed old surgical scars in bilateral scrotal lateral walls, and a tender nodule, approximately $0.3 \mathrm{~cm} \times 0.3 \mathrm{~cm}$ in size, in the right scrotum, which was demarcated by the right testis and epididymis upon palpation. Given the concern for malignancy, some necessary laboratory tests were conducted. The value of ß-human chorionic gonadotropin ( $\$-\mathrm{hCG}$ ) was $1.8 \mathrm{mU} / \mathrm{mL}$ (normal range: $0-3.2 \mathrm{mU} / \mathrm{mL}$ for males), of alpha fetoprotein (AFP) was $18.4 \mu \mathrm{g} / \mathrm{L}$ (normal range: less than $25 \mu \mathrm{g} / \mathrm{L}$ ), and of lactic acid dehydrogenase (LDH) was 177 U/L (normal range: 135-215 U/L), and the other laboratory tests, such as blood routine examination, urinalysis, and coagulation function tests were normal. Color Doppler ultrasound showed bilateral epididymal tubular ectasia and no other information concerning the tender nodule in the right scrotum was detected (Figure 1). In light of the EAU guidelines on vasectomy and other pertinent literature (4-7), ibuprofen (200 $\mathrm{mg}$, once a day) was administered orally to this patient for 2 months, but pain relief was not obvious. Then, we performed spermatic cord block with lidocaine, dexamethasone and gentamicin, which significantly alleviated the patient's pain symptoms. After detailed medical consultations and communication, the patient signed an informed consent form and agreed to undergo resection of the painful nodule in the right vas deferens. We made a $2.5 \mathrm{~cm}$ incision in the high lateral wall of the right scrotum and isolated the two ends of the 
vas deferens. The right painful nodule was located at the proximal vas deferens stump and was well circumscribed intraoperatively by a faint yellow capsule with the size of $0.3 \mathrm{~cm} \times 0.4 \mathrm{~cm}$ grossly. We isolated this lesion along the yellow capsule and cut it with tissue scissors; then, we ligated the proximal stump again with silk sutures. After resection of the lesion, we still explored the right epididymis and testis and found that the epididymis was mildly swollen. Moreover, the morphology and color of the right testis were normal. Postoperative pathological examinations revealed that the nodule was an arteriovenous haemangioma (Figure 1). There were no obvious complications postoperatively and scrotal pain was relieved significantly 1 month later. All procedures performed in studies involving human participants were in accordance with the ethical standards of the institutional and/or national research committee(s) and with the Helsinki Declaration (as revised in 2013). Written informed consent was obtained from the patient.

\section{Discussion}

Haemangioma is a benign tumor composed of dilated vessel lumina and relatively thin walls that is common in the dermis of the face, head, trunk and extremities $(1-3,8)$. Although it could theoretically involve any organs in the body (9), haemangioma is a rare entity in the urinary and male reproductive systems. Kryvenko (10) once described 8 cases of haemangioma derived from testes and all lesions in the testes were recognized by ultrasound, so he believed that clinical physical examination and imageological examination could suggest haemangioma preoperatively. Other researchers $(1,3,8)$ have reported that haemangioma in the testes or epididymis is difficult to distinguish from other malignancies due to the rarity and lack of characteristic imaging findings, even though the levels of $\mathrm{B}-\mathrm{hCG}$, AFP, and $\mathrm{LDH}$ are within normal limits. Hitherto, this is the first report of haemangioma of the vas deferens in the English literature, which we discovered in a male patient with a history of vasectomy. Preoperatively, considering the history of vasectomy, the near-term MRI examination report, the ultrasonography and the four years of intermittent pain symptom, we speculated that the painful nodule in the right scrotum was spermatic granuloma, which is a common cause in patients with post-vasectomy pain syndrome (PVPS) due to inflammation and sperm leakage from the proximal stump of the vas deferens $(6,7,11)$.Unexpectedly, the post-operative pathological examination revealed that the lesion was an arteriovenous haemangioma.

Although we failed to detect the painful nodule in the vas deferens in our case, conventional color Doppler ultrasound could reveal abundant information about lesions in the genitourinary system, including the position, size, texture, blood signals, and relationships with surrounding structures, preoperatively (12). Interestingly, Frates (13) performed scrotal ultrasound in 345 male patients, and found mobile echogenicities in the epididymis of those who had previously undergone vasectomy. Therefore, he thought mobile echogenicities were probably related to clumps or clusters of spermatozoa. Contrast-enhanced ultrasound (CEUS) is a new imaging method that is widely accepted for its safety and accuracy (14). Yang (15) once succeeded in diagnosing a case of thyroid haemangioma with CEUS preoperatively, and believed that the "slow in and slow out" pattern of contrast filling and perfusion was the characteristic feature of haemangioma. $\mathrm{Wu}$ (16) summarized the typical features of liver haemangioma as peripheral nodular and centripetal enhancement during the arterial phase followed by hyperor isoenhancement during the portal venous and late phases on CEUS. MRI, especially enhanced MRI can also provide valuable diagnostic information for haemangioma before surgery $(1-3,17)$. Intense heterogeneous contrast enhancement was found on T1 weighted images, while T2 weighted images demonstrated hypointensity of this lesion (3). It is believed that the golden criteria of diagnosis of haemangioma is pathological examination. In addition to dilated lumina, thin walls, and vascular endotheliocytes proliferations, immunohistochemistry staining results can further confirm the diagnosis of haemangioma in the genitourinary system, including positive CD31, CD34, FVIII-related protein positivity $(3,10)$

The 2012 AUA guidelines on vasectomy (18) mentioned that approximately $1-2 \%$ of men who underwent vasectomy suffered from severe chronic scrotal pain, currently referred to as PVPS. PVPS was defined as more than 3 months of constant or intermittent scrotal content discomfort or pain, severe enough to interfere with daily activities and prompting patients to seek medical attention $(5,19,20)$. Tandon $(6)$ and Tan $(5,19)$ summarized the possible pathophysiological mechanisms of PVPS as follows: (I) Back pressure increments in an obstructed proximal vas deferens and epididymis, leading to epididymal interstitial fibrosis and scrotal pain. This could perfectly explain the intermittent pain induced by heavy physical labor or sexual intercourse in our case, causing sympathetic nervous excitement and subsequent epididymal and vas deferential 
smooth muscle contraction. (II) Due to the rupture of epididymal ducts and extravasation of sperm, local inflammation could result in local painful nodules. This is why the resection of sperm granuloma could sometimes alleviate the symptoms of individuals with PVPS; (III) The nerves around the vas deferens or epididymis are densely encased in fibrous tissue, with distortion, angulation and lymphatic infiltration. This is the theoretical basis and feasibility for micro-denervation of the spermatic cord for PVPS management.

In terms of the treatment for PVPS, non-surgical treatment should be the first choice for the management of PVPS $(5,6,20,21)$. If non-surgical treatment failed to control symptoms, patients with PVPS might benefit from surgical therapies, which included resection of nodules or granulomas, vasectomy reversal, spermatic cord denervation, epididymectomy, and orchiectomy $(5-7,12,19-22)$. Tan $(5,19,20)$ emphasized that diagnostic spermatic cord block should be performed prior to surgical therapy and surgeries could be performed only with obvious improvements in pain from spermatic cord block. In this case, we first administered NSAIDs (ibuprofen) to the patient for more than 2 months with frustrating outcomes and then spermatic cord block achieved tentative satisfactory results. Finally, under medical advice, the patient chose resection of the painful nodule which was proven to be arteriovenous haemangioma instead of spermatic granuloma by postoperative pathology. Staggers (23) once reported a capillary haemangioma of the finger in an adult after a burn. Several cerebral cavernous angiomas have been reported in individuals who underwent brain radiotherapy for glioma or other malignancies $(24,25)$. Therefore, we boldly hypothesize that the haemangioma might be associated with thermal injury caused by a burn, radiation or electrotome cauterization. Due to the lack of sufficient haemangioma cases, this hypothesis needs to be proven by basic research or cohort studies in the future.

The objective of this article is to remind urologists and oncologists that haemangiomas could involve in the vas deferens and, an addition to the spermatic granuloma, might be one reason for PVPS. Cauterization of the vas deferens might have a potential relationship with haemangioma.

\section{Acknowledgments}

We thank Yongfu Mao for his guidance with writing and Yushi Yang for his help with the pathological staining. Funding: This work was supported by the 1.3 .5 project for disciplines of excellence, West China Hospital, Sichuan University (ZY2016104) and Pillar Program from Department of Science and Technology of Sichuan Province (2018SZ0219).

\section{Footnote}

Reporting Checklist: The authors have completed the CARE and SCARE reporting checklists. Available at http://dx.doi. org/10.21037/tau-20-1156

Peer Review File: Available at http://dx.doi.org/10.21037/tau20-1156

Conflicts of Interest: All authors have completed the ICMJE uniform disclosure form (available at http://dx.doi. org/10.21037/tau-20-1156). The authors have no conflicts of interest to declare.

Ethical Statement: The authors are accountable for all aspects of the work in ensuring that questions related to the accuracy or integrity of any part of the work are appropriately investigated and resolved. All procedures performed in studies involving human participants were in accordance with the ethical standards of the institutional and/or national research committee(s) and with the Helsinki Declaration (as revised in 2013). Written informed consent was obtained from the patient.

Open Access Statement: This is an Open Access article distributed in accordance with the Creative Commons Attribution-NonCommercial-NoDerivs 4.0 International License (CC BY-NC-ND 4.0), which permits the noncommercial replication and distribution of the article with the strict proviso that no changes or edits are made and the original work is properly cited (including links to both the formal publication through the relevant DOI and the license). See: https://creativecommons.org/licenses/by-nc-nd/4.0/.

\section{References}

1. Karray O, Ben Chehida MA, Sellami A, et al. A Rare Scrotal Tumor: Epididymal Cavernous Hemangioma. Case Rep Urol 2018;2018:4259563.

2. Vavallo A, Lafranceschina F, Lucarelli G, et al. Capillary hemangioma of the scrotum mimicking an epididymal tumor: case report. Arch Ital Urol Androl 2014;86:395-6.

3. Wong NC, Dason S, Pozdnyakov S, et al. Capillary 
hemangioma of the testis: A rare benign tumour. Can Urol Assoc J 2015;9:133-5.

4. Dohle GR, Diemer T, Kopa Z, et al. European Association of Urology guidelines on vasectomy. Eur Urol 2012;61:159-63.

5. Tan WP, Levine LA. An overview of the management of post-vasectomy pain syndrome. Asian J Androl 2016;18:332-7.

6. Tandon S, Sabanegh E Jr. Chronic pain after vasectomy: a diagnostic and treatment dilemma. BJU Int 2008;102:166-9.

7. Granitsiotis P, Kirk D. Chronic testicular pain: an overview. Eur Urol 2004;45:430-6.

8. Hugar SB, Kadow BT, Davis A, et al. Pediatric Testicular Hemangioma in a 10-Year-old: A Rare Entity That May Mimic Malignancy With Appraisal of the Literature. Urology 2018;114:175-80.

9. Drolet BA, Esterly NB, Frieden IJ. Hemangiomas in children. N Engl J Med 1999;341:173-81.

10. Kryvenko ON, Epstein JI. Testicular hemangioma: a series of 8 cases. Am J Surg Pathol 2013;37:860-6.

11. Kathrins M. Technics and complications of elective vasectomy: the role of spermatic granuloma in spontaneous recanalization. Fertil Steril 2016;106:68-9.

12. Strebel RT, Leippold T, Luginbuehl T, et al. Chronic scrotal pain syndrome: management among urologists in Switzerland. Eur Urol 2005;47:812-6.

13. Frates MC, Benson CB, Stober SL. Mobile echogenicities on scrotal sonography: is the finding associated with vasectomy? J Ultrasound Med 2011;30:1387-90.

14. Sekej M, Vadnjal Đonlagić S, Ključevšek D. ContrastEnhanced Ultrasound for the Characterization of Infantile Hepatic Hemangioma in Premature Neonate. Cureus 2020;12:e9580.

15. Yang DB, Lan HF, Shi PD, et al. Evaluation of thyroid

Cite this article as: Zhang F, Bai Y, Wang X, Tang Y, Yang Y, Hu H, Chen Z, Li A, Li D, Feng D, Yang Z, Han P. Arteriovenous haemangioma of the vas deferens: a case report and literature review. Transl Androl Urol 2021;10(1):527-531. doi: $10.21037 /$ tau-20-1156 hemangioma by conventional ultrasound combined with contrast-enhanced ultrasound: a case report and review of the literature. J Int Med Res 2020;48:300060520954718.

16. Wu XF, Bai XM, Yang W, et al. Differentiation of atypical hepatic hemangioma from liver metastases: Diagnostic performance of a novel type of color contrast enhanced ultrasound. World J Gastroenterol 2020;26:960-72.

17. Léauté-Labrèze C, Harper JI, Hoeger PH. Infantile haemangioma. Lancet 2017;390:85-94.

18. Sharlip ID, Belker AM, Honig S, et al. Vasectomy: AUA guideline. J Urol 2012;188:2482-91.

19. Tan WP, Tsambarlis PN, Levine LA. Microdenervation of the spermatic cord for post-vasectomy pain syndrome. BJU Int 2018;121:667-73.

20. Tan WP, Levine LA. Micro-Denervation of the Spermatic Cord for Post-Vasectomy Pain Management. Sex Med Rev 2018;6:328-34.

21. Tu XA, Zhao L, Zhao LY, et al. Microsurgical vasovasostomy for the treatment of intractable chronic scrotal pain after vasectomy. Asian J Androl 2013;15:850-1.

22. Polackwich AS, Tadros NN, Ostrowski KA, et al. Vasectomy Reversal for Postvasectomy Pain Syndrome: A Study and Literature Review. Urology 2015;86:269-72.

23. Staggers JR, Pearson JM, Chaudhari NM. Capillary Hemangioma of the Finger in an Adult after a Burn: A Unique Case Mimicking Pyogenic Granuloma. J Orthop Case Rep 2019;9:3-5.

24. Mariniello G, De Liso M, Russo C, et al. Radiation-induced brain cavernomas in elderly: review of the literature and a rare case report. Acta Biomed 2019;90:77-83.

25. Paiva A, Lovato R, Araujo J, et al. Septum Pellucidum Cavernoma: A Case Report and Anatomical Consideration of an Extremely Rare Lesion. Turk Neurosurg 2020;30:145-8. 